\title{
Moving the Goalposts: Possible Effects of Changes in Opportunity Costs on Conservation Triage
}

\author{
Paul Woodcock ${ }^{1 *}$ and Matt W. Hayward ${ }^{1,2}$ \\ 'School of Environment, Natural Resources and Geography, College of Natural Sciences, Bangor University, Bangor, UK, \\ ${ }^{2}$ Centre for African Conservation Ecology, Nelson Mandela Metropolitan University, Port Elizabeth, South Africa
}

Keywords: triage, prioritization, conservation planning, extinction, uncertainty, strategic foresight

OPEN ACCESS

Edited by:

James Guy Castley,

Griffith University, Australia

Reviewed by:

Carly Cook

Monash University, Australia

*Correspondence:

Paul Woodcock

paulwoodcock119@yahoo.co.uk

Specialty section:

This article was submitted to

Conservation

a section of the journal

Frontiers in Ecology and Evolution

Received: 22 April 2016 Accepted: 13 September 2016

Published: 28 September 2016

Citation:

Woodcock P and Hayward MW (2016) Moving the Goalposts:

Possible Effects of Changes in

Opportunity Costs on Conservation

Triage. Front. Ecol. Evol. 4:113.

doi: 10.3389/fevo.2016.00113
The resources required to halt biodiversity declines are estimated to be many times more than current investment, underpinning calls to increase financial support for conservation, and to develop methods for allocating funds more efficiently (McCarthy et al., 2012; McDonald et al., 2015). Conservation triage is an important part of the latter strategy, with proponents arguing that by explicitly prioritizing resources toward targets (e.g., particular species or populations) identified as generating the greatest benefits for a given investment, triage avoids using resources on cases in which conservation effort is unlikely to make a difference (i.e., improvement is unlikely or is near-certain irrespective of investment; Bottrill et al., 2008; Schneider et al., 2010; Gerber, 2016). However, triage has been criticized on several grounds, such as potentially signaling to decision-makers that some extinctions or population losses are acceptable, and the scientific, ethical, and practical arguments have been debated without reaching clear consensus (Bottrill et al., 2008; Jachowski and Kesler, 2008; Parr et al., 2008). Our primary aim here is not to revisit these arguments, but to highlight an additional issue-the potential for substantial, unforeseen changes in the future costs of conservation-and investigate how this issue might affect triage and non-triage approaches.

\section{CHANGES IN OPPORTUNITY COSTS}

Species conservation ultimately requires habitat to be protected within which threatened populations can persist. Protecting this habitat for conservation therefore often involves forgoing activities that would yield economic benefits (in the short-medium term at least), e.g., mining, conversion to agriculture etc. The need to consider these forgone revenues-or opportunity costsis recognized in the broader land-use planning literature (Cameron et al., 2008; Wilson et al., 2010; Mazor et al., 2014), and triage assessments can include opportunity costs for conserving particular sites (Schneider et al., 2010). Although this research can consider several alternative levels of opportunity cost, future costs can be both difficult to predict and variable. For example, short-term spikes in demand for oil, minerals, cash crops etc. can result from changes in economic pressures or shifting political priorities that may be difficult to foresee at the time triage plans are formulated. More permanent increases in opportunity costs can also occur as new resources are discovered and existing resources are used in novel ways (e.g., increasing demand for rare earth metals for new technologies; Service, 2010; Sutherland et al., 2012; Campbell, 2014). Large increases in the potential financial returns from resource exploitation raise the costs of protecting habitats and create pressure to use land or sea for purposes that are detrimental to conservation. Indeed, the tripling of gold prices during the global financial crisis is argued to have been an important driver of Amazonian deforestation from 2007-2013 (Alvarez-Berrios and Aide, 2015), whilst economic pressures such as 
oil and gas exploitation have led to the downgrading, downsizing, and degazettement of protected areas across the globe (Symes et al., 2016).

\section{IMPLICATIONS OF CHANGING OPPORTUNITY COSTS FOR TRIAGE}

Effective triage-based prioritization requires knowledge of both the resources available to conservation and the likely costs. Whilst the extent to which conservation funding can be accurately predicted over time has been highlighted as a potential weakness in triage (Parr et al., 2008), there has been less consideration of the importance of accurate information on conservation costs, and particularly the future opportunity costs associated with protecting the habitats in which populations and species conserved under triage can persist. Uncertainty in future opportunity costs can be incorporated into triage assessments by determining the most efficient approach to protecting particular populations or species under a range of scenarios. However, the most effective triage strategy can be influenced by which cost scenario is ultimately used, and individual scenarios may not consider the potential for marked fluctuations in costs. Unanticipated increases in opportunity costs (even if transient) are a particular problem if funding no longer offsets the revenues forgone by conserving the habitats required by the populations/species protected under the original plan. Importantly, the initial acceptance of triage could undermine justifications for additional resources. The logical continuation of triage seems to then imply a re-prioritization, in which the loss of further populations/species is accepted as inevitable because rising opportunity costs can no longer be offset with the available funding. This would not only erode the conservation benefits from triage, it could also generate a revised protection plan that is less efficient than would have been achieved if future opportunity costs had been established more accurately initially.

\section{IMPLICATIONS OF CHANGING OPPORTUNITY COSTS FOR NON-TRIAGE APPROACHES}

Approaches to species conservation without a formal triage-type prioritization do not expressly accept that some populations or species cannot be conserved. As such, if rising opportunity costs exceed existing funding, these approaches do not necessarily imply the type of re-prioritization suggested by triage, and instead may perhaps be better able to justify arguing for additional funding. Equally however, the success of philosophies that reject triage arguments will still be affected if the funding needed to conserve particular populations increases due to rising opportunity costs. In these circumstances, sufficient public and political support to continue protection despite rising opportunity costs would be needed: contemporary impacts on protected areas (Symes et al., 2016) illustrate the difficulties of maintaining such support in the face of increasing economic pressures.

\section{PLANNING FOR UNCERTAINTY IN FUTURE OPPORTUNITY COSTS}

Irrespective of whether triage or non-triage approaches are used, one response to the risk posed by unexpected increases in opportunity costs may be to place greater emphasis on anticipating and planning for uncertainty through strategic foresight. This could involve methods such as horizon scanning (e.g., to identify possible novel uses of resources; Sutherland and Woodroof, 2009), understanding drivers of current and future trends in opportunity costs, and building a range of scenarios including low probability-high impact events (see Cook et al., 2014a,b for detailed discussion of the range of techniques used within strategic foresight approaches). Based on this information, contingency plans can be developed that include strategies to preempt or respond to unexpected future increases in opportunity costs. For example, triage might also consider the risk from spikes in land use values and whether or not long-term guarantees can be provided in such situations for populations/species protected under the initial plan. Updating contingency plans periodically would also be pivotal to ensuring that new potential risks are identified, evaluated, and mitigated.

\section{CONCLUSIONS}

In general, we support the view that triage is compatible with other approaches to conservation (McCarthy, 2014). However, we feel that triage-based approaches may risk unwanted conservation outcomes if opportunity costs rise unexpectedly in the future, particularly given the impacts such economic drivers continue to have across the world. Moreover, because longterm habitat protection is vital, we suggest strategic foresight approaches that identify risks from potential future increases in opportunity costs and include contingency plans should be more widely incorporated into triage prioritization.

\section{AUTHOR CONTRIBUTIONS}

$\mathrm{MH}$ and PW jointly discussed and designed the manuscript. PW wrote the initial draft. PW and $\mathrm{MH}$ both contributed to subsequent revisions.

\section{FUNDING}

$\mathrm{MH}$ was supported by the Centre for African Conservation Ecology, Nelson Mandela University.

\section{ACKNOWLEDGMENTS}

We are very grateful to Carly Cook for the helpful and constructive comments provided during the review of this manuscript. 


\section{REFERENCES}

Alvarez-Berrios, N. L., and Aide, T. M. (2015). Global demand for gold is another threat for tropical forests. Environ. Res. Lett. 10:014006. doi: 10.1088/17489326/10/1/014006

Bottrill, M. C., Joseph, L. N., Carwardine, J., Bode, M., Cook, C., Game, E. T., et al. (2008). Is conservation triage just smart decision making? Trends Ecol. Evol. (Amst). 23, 640-654. doi: 10.1016/j.tree.2008.07.007

Cameron, S. E., Williams, K. J., and Mitchell, D. K. (2008). Efficiency and concordance of alternative methods for minimizing opportunity costs in conservation planning. Conserv. Biol. 22, 886-896. doi: 10.1111/j.15231739.2008.00982.x

Campbell, G. A. (2014). Rare earth metals: a strategic concern. Miner. Econ. 27, 21-31. doi: 10.1007/s13563-014-0043-y

Cook, C. N., Inayatullah, S., Burgman, M. A., Sutherland, W. J., and Wintle, B. A. (2014b). Strategic foresight: how planning for the unpredictable can improve environmental decision-making. Trends Ecol. Evol. 29, 531-541. doi: 10.1016/j.tree.2014.07.005

Cook, C. N., Wintle, B. C., Aldrich, S. C., and Wintle, B. A. (2014a). Using strategic foresight to assess conservation opportunity. Conserv. Biol. 28, 1474-1483. doi: 10.1111/cobi.12404

Gerber, L. R. (2016). Conservation triage or injurious neglect in endangered species recovery. Proc. Natl. Acad. Sci. 113, 3563-3566. doi: 10.1073/pnas.1525085113

Jachowski, D. S., and Kesler, D. C. (2008). Allowing extinction: should we let species go? Trends Ecol. Evol. 24, 180. doi: 10.1016/j.tree.2008.11.006

Mazor, T., Giakoumi, S., Kark, S., and Possingham, H. P. (2014). Large-scale conservation planning in a multinational marine environment: cost matters. Ecol. Appl. 24, 1115-1130. doi: 10.1890/13-1249.1

McCarthy, D. P., Donald, P. F., Scharlemann, J. P., Buchanan, G. M., Balmford, A., Green, J. M., et al. (2012). Financial costs of meeting global biodiversity conservation targets: current spending and unmet needs. Science 16, 946-949. doi: $10.1126 /$ science. 1229803

McCarthy, M. A. (2014). Contending with uncertainty in conservation management decisions. Ann. N.Y. Acad. Sci. 1322, 77-91. doi: $10.1111 /$ nyas. 12507

McDonald, J. A., Carwardine, J., Joseph, L. N., Klein, C. J., Rout, T. M. et al. (2015). Improving policy efficiency and effectiveness to save more species: a case study of the megadiverse country Australia. Biol. Conserv. 182, 102-108. doi: 10.1016/j.biocon.2014.11.030

Parr, M. J., Bennun, L., Boucher, T., Brooks, T., Chutas, C. A., Dinerstein, E., et al. (2008). Why we should aim for zero extinction. Trends Ecol. Evol. 24, 181. doi: 10.1016/j.tree.2009.01.001

Schneider, R. R., Hauer, G., Adamowicz, W. L., and Boutin, S. (2010). Triage for conserving populations of threatened species: the case of woodland caribou in Alberta. Biol. Conserv. 143, 1603-1611. doi: 10.1016/j.biocon.2010.04.002

Service, R. F. (2010). Nations move to head off shortages of rare earths. Science 327, 1596-1597. doi: 10.1126/science.327.5973.1596

Sutherland, W. J., Aveling, R., Bennun, L., Chapman, E., Clout, M., Côté, I. M., et al. (2012). A horizon scan of global conservation issues for 2012. Trends Ecol. Evol. 27, 112-118. doi: 10.1016/j.tree.2011.10.011

Sutherland, W. J., and Woodroof, H. J. (2009). The need for environmental horizon scanning. Trends Ecol. Evol. 24, 523-527. doi: 10.1016/j.tree.2009.04.008

Symes, W. S., Rao, M., Mascia, M. B., and Carrasco, L. R. (2016). Why do we lose protected areas? factors influencing protected area downgrading, downsizing and degazettement in the tropics and subtropics. Glob. Change Biol. 22, 656-665. doi: 10.1111/gcb.13089

Wilson, K. A., Meijaard, E., Drummond, S., Grantham, H. S., Boitani, L., Catullo, G., et al. (2010). Conserving biodiversity in production landscapes. Ecol. Appl. 20, 1721-1732. doi: 10.1890/09-1051.1

Conflict of Interest Statement: The authors declare that the research was conducted in the absence of any commercial or financial relationships that could be construed as a potential conflict of interest.

The handling Editor declared a collaboration with one of the authors $\mathrm{MH}$ and states that the process nevertheless met the standards of a fair and objective review.

Copyright $(0) 2016$ Woodcock and Hayward. This is an open-access article distributed under the terms of the Creative Commons Attribution License (CC BY). The use, distribution or reproduction in other forums is permitted, provided the original author(s) or licensor are credited and that the original publication in this journal is cited, in accordance with accepted academic practice. No use, distribution or reproduction is permitted which does not comply with these terms. 